www.jmscr.igmpublication.org

Impact Factor 5.84

Index Copernicus Value: 83.27

ISSN (e)-2347-176x ISSN (p) 2455-0450

crossref DOI: _https://dx.doi.org/10.18535/jmscr/v5i4.14

Journal Of Medical Science And Clinical Research

\title{
A Duodecennial Era without Diagnosis: A Case Report On Sheehan Syndrome
}

Authors

Sanjeev Kumar ${ }^{1}$, Abhinandya Mukhopadhyay ${ }^{2}$, Dr G.N.Dubey ${ }^{3}$, Dr B.K.Singh ${ }^{4}$

${ }^{1}$ Junior Resident, Dept of General Medicine, Darbhanga Medical College, Bihar

${ }^{2}$ Junior Resident, Dept of General Medicine, DMCH, Bihar

${ }^{3}$ Senior Resident, Dept of General Medicine, DMCH

${ }^{4}$ Professor and HOD, Dept of General Medicine, DMCH

\begin{abstract}
Varying degree of deficiency of anterior pituitary secreted hormone due to ischemic gland tissue death in postpartum period predominantly caused by massive intrapartum and postpartum haemorrhage is defined as Sheehan's syndrome. The onset and mode of presentation are variable with abrupt or insidiously developing partial or complete pituitary insufficiency. In developing countries it is still prevalent due to lack of effective maternal care. Here we report a forty five year old lady who has been diagnosed with this syndrome twelve years after having severe haemorrhage associated with delivery. We emphasize on clinical awareness regarding the condition among all levels of health care providers, since Sheehan's syndrome may present as neurological and endocrinological emergency with life threatening potentials]

Sheehan's syndrome is a condition that effects women who lose a life-threatening amount of blood in childbirth or who have severe low blood pressure during or after childbirth, which can deprive the body of oxygen. In Sheehan's syndrome, the lack of oxygen damages pituitary gland, rendering the gland unable to produce enough pituitary hormones. ${ }^{[1]}$ It is still a burdensome health problem, specially in developing countries like India due to lack of effective obstetric care and consciousness. The clinical presentation is variable; typically appear slowly, after a period of months even years and sometimes right away; like inability to breast feed.[2,3]Diagnosis is based on clinical features and laboratory finding of decreased hormone levels along with suggestive obstetric history and radiologic feature. ${ }^{[4]} D$ Treatment requires lifelong replacement of deficient hormones.
\end{abstract}

\section{CASE PRESENTATION}

A 45 years old lady, having 2 living children, resident of district Madhubani, state; Bihar presented to the Medicine emergency department with complain of lethargy and extreme weakness. The patient was unable to stand up from lying down position for last two days according to the patients attendant. Patient's attendant complained that the patient had been suffering frequent attacks of such weakness and unconsciousness for last 1012 years which improved after intravenous fluid administration and off and on administration of injectable preparation of hydrocortisone and dexamethasone by some local practitioner. The attendant also complained of progressive lethargy, loss of appetite, lack of interest in all pleasurable 
activity. Surprisingly the patient complained of weight gain in recent years. In last 10 years, the patient has visited a number of government and non government facilities and has been diagnosed as depressive illness maximum times. There was no history of fever, bleeding from anywhere, pain in anywhere of the body, breathlessness, vomiting or diarrhoea. There is no history of any chronic disease like tuberculosis, diabetes mellitus, hypertension.

On inquiry on menstrual history, patient informed that patient is amenorrheic for last 12 years after home delivery of a dead child. On further inquiry of about the incidence, patient intimated that patient had heavy vaginal bleeding followed by unconsciousness and cessation of urine output. For that reason, patient was taken to hospital, where patient improved after intravenous fluid administration, blood transfusion and other conservative measurements.

On examination, patient had a pulse rate 70 per minute, blood pressure $70 / 40 \mathrm{~mm}$ of $\mathrm{Hg}$. The patient was ill looking, had generalized non pitting edema, skin was pale with absence of hair from skin, axillae and groin and loss of eyebrows on lateral side. The examination of heart, lungs and abdomen were normal. On examination of CNS patient had no focal neurological deficit. Relaxation of planter jerk and ankle jerk were delayed.

On investigation following results were found:

\begin{tabular}{|l|l|}
\hline $\mathrm{Hb}$ & $8 \mathrm{gm} / \mathrm{dl}$ \\
$\mathrm{MCV}$ & $83 \mathrm{fl}$ \\
$\mathrm{MCHC}$ & $33.2 \mathrm{gm} / \mathrm{dl}$ \\
Peripheral blood smear & $\begin{array}{l}\text { Normocytic normochromic } \\
\text { anaemia }\end{array}$ \\
\hline TLC & $7400 / \mathrm{cumm}$ \\
\hline DLC & $\mathrm{N} 76 \mathrm{~L} 21 \mathrm{E} 1 \mathrm{~B} 1 \mathrm{M} 1$ \\
\hline Platelet count & $1,50,000 / \mathrm{cumm}$ \\
RBS & $58 \mathrm{mg} / \mathrm{dl}$ \\
Serum Na+ & $110 \mathrm{meq} / \mathrm{L}$ \\
Serum K+ & $4.2 \mathrm{meq} / \mathrm{L}$ \\
\hline LFT & Within normal limit \\
\hline RFT & Within normal limit \\
\hline Chest X-Ray & Within normal limit \\
ECG of 12 leads & Within normal limit \\
USG Whole abdomen & Normal,endometrial \\
& thickness 5 mm
\end{tabular}

On the basis of results of basic examination and investigation hormonal assay was done. The results of hormonal assay was as follows:

\begin{tabular}{|l|l|l|}
\hline Hormone & $\begin{array}{l}\text { Measured } \\
\text { value }\end{array}$ & Reference range \\
TSH(microIU/mL) & 0.1 & $0.4-4.5$ \\
FT3 $(\mathrm{Pg} / \mathrm{mL})$ & 1.08 & $2.0-4.4$ \\
FT4(ng/dL) & 0.6 & $0.93-1.7$ \\
\hline FSH(mIU/mL) & 3.5 & $\begin{array}{l}27.72-133.4(\mathrm{in} \\
\text { menopause) }\end{array}$ \\
\hline LH(mIU/mL) & 1.1 & $\begin{array}{l}10.39-64.57(\mathrm{in} \\
\text { menopause) }\end{array}$ \\
\hline $\begin{array}{l}\text { Serum cortisol(at } 8.00 \\
\text { a.m.)(mcg/mL) }\end{array}$ & 0.01 & $3.7-18.4$ \\
\hline $\begin{array}{l}\text { ACTH(moming } \\
\text { level)(pg/mL) }\end{array}$ & 0 & $5-27$ \\
\hline Growth hommone(ng/mL) & 0.09 & $0.06-5.00$ \\
\hline Prolactin(ng/mL) & 0.90 & $3.46-19.40$ \\
\hline
\end{tabular}

On the basis of laboratory investigations a central cause resulting in panhypopituitarism was suspected.MRI whole brain was ordered which showed empty sella turcica confirming diagnosis of Sheehan's syndrome.

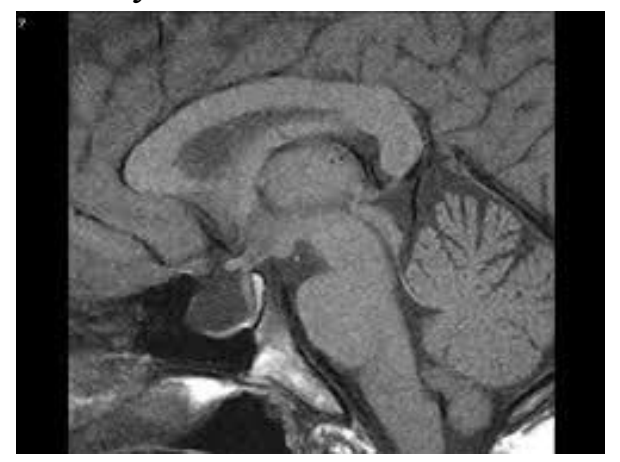

Fig 1: MRI Picture showing empty sella

\section{DISCUSSION}

In 1937 Sheehan reported 11 cases of women who died In the puerperium, all of whom had necrosis of the anterior pituitary gland-adenohypoohysis. Nine of them had severe haemorrhage at delivery. Postpartum hypopituitarism has been known as Sheehan's Syndrome since then ${ }^{[1]}$. Sheehan's syndrome is now uncommon in developed countries; but still is a major problem in developing countries. The pituitary gland is physiologically enlarged in pregnancy and therefore very sensitive to decrease in blood flow. Decreased blood flow to the gland resulting in infarction of gland tissue is the most accepted mechanism of Sheehan's syndrome. though vasospasm, autoimmunity, disseminated intravas- 
cular coagulation all may have a role in development of Sheehan's syndrome, none was conclusively proven. Women with Sheehan's syndrome have varying degrees of hypopituitarism, ranging from panhypopituitarism to only selective pituitary deficiencies. The anterior pituitary is more susceptible to damage than the posterior pituitary. ${ }^{[5]}$ Pituitary hormones regulate the rest of the endocrine system and control metabolism, fertility, blood ,breast milk production and nany other vital processes. Hormones from anterior pituitary include:

Growth hormone $(\mathrm{GH})$ : This control bone and tissue growth.

Thyroid stimulating hormone (TSH):This hormone stimulates thyroid gland to produce key hormones regulating metabolic activity of whole body.

Luteinizing hormone (LH): Controls reproductive activity in women.

Follicle stimulating hormone (FSH): Working with LH, FSH regulates ovulation and reproductive activity in women.

Adrenocorticotropic hormone (ACTH): This hormone stimulates adrenal gland to produce cortisol and other hormones, thus regulating blood pressure, immune regulation and stress response Prolactin: This hormone regulates development of female breast and lactation. Signs and symptoms of Sheehan syndrome commonly appear slowly, after a period of months or even years. But sometimes problems appear right away leading to lactational failure. ${ }^{[6]}$ The symptoms vary from patient to patient and are due to deficiency of hormones. They include:

Difficulty in breast feeding

Amenorrhea or oligomenorrhea

Slowed mental function,

Weight gain and feeling of cold Low blood sugar (hypoglycaemia)

Low blood pressure (hypotension)

Fatigue

Irregular heartbeat ${ }^{[7,8]}$

Adrenal crisis: It is a serious complication causing sudden, life threatening state that can lead to extremely low blood pressure, shock, coma and even death. Adrenal crisis occurs when body is under marked stress and adrenal gland is unable to produce cortisol, a powerful stress hormone. ${ }^{[7,9]}$

For many women, like our patient symptoms are non specific. They present to health care facility mainly due to following reason: Menstrual irregularities, Uninted weight loss or gain. Diagnosis of Sheehan's syndrome is often difficult and needs a thorough medical history, hormonal assay and imaging studies. Free T3,Free T4, TSH, cortisol, ACTH, FSH,LH, oestrogen, prolactin, insulin like growth factor- $1 .{ }^{[10,12]} \mathrm{A}$ dynamic pituitary function test like insulin tolerance test (ITT) is helpful to assess pituitary reserve of $\mathrm{GH}$ and $\mathrm{ACTH} .{ }^{[8]}$ level of prolactin is also important to exclude prolactinoma, a known cause of panhypopituitarism. Non specific haematological findings are common in Sheehan syndrome. Gokalp et al. in 2009 showed that $80 \%$ of study population with this syndrome have anaemia. ${ }^{[11]}$ Similar was presention in our patient. Leucopenia and thrombocytopenia were also commonly found in these patients. These haematologic findings, not resolving to standard therapy often leads to further investigation like hormonal assay. The neuro imaging findings are distinctive of Sheehan's syndrome. In pregnancy, there is enlargement of pituitary from diffuse nodular hyperplasia of prolactin secreting cells. The MRI shows the pituitary gland to be largest in immediate postpartum period with a convex appearance. After delivery the pituitary returns to normal size. In chronic form of Sheehan's syndrome, neuro imaging classically shows atrophy of pituitary gland and an empty sella, as was found in our patient. ${ }^{[10,13,14]}$ The treatment of Sheehan syndrome is by replacement of deficient hormones. ACTH and TSH deficiency should be replaced with with glucocorticoids and levothyroxine. Mineral corticoid is not needed usually. Sex hormones are often replaced in premenopausal women. Our patient showed a marked improvement in symptoms and signs within few weeks after replacem It is important to 
emphasize careful and meticulous review of medical history, physical examination of syndrome among health care providers.

\section{REFERENCES}

1. Sheehan HL.Postpartum necrosis of the anterior pituitary.Journal of Pathology and Bacteriology, 1937;45:189-214

2. Ozbey $\mathrm{N}$,Inanc $\mathrm{S}$,Aral $\mathrm{F}$,et al:Clinical and laboratory evaluation of 40 patients with Sheehan's syndrome.Isr.J.Med.Sci.1994; 30:826-9

3. Lakhadar AA,McLauren EH,Davda NS, McKay EJ,Rubin PC.Pituitary failure from Sheehan's syndrome in the puerperium. Two case reports.British journal of obstetrics and gynaecology 1987;37:223-7

4. DiZerega G,Kletzky OA,Mishell DR.Diagnosis of Sheehan's syndrome using sequential pituitary stimulation tests. Am. J. Obstet. Gynecol 1978;132:348-53

5. Kelestimur F. Sheehan's syndrome. Pituitary 2003;6:181-188

6. Dejager S,Gerber S,Foubert L,Turpin G.Sheehan's syndrome:differential diagnosis in the acute phase.J. Internal Med.1998;244:261-6

7. Lamberts SW, de Herder WW,van der Lely AJ.Pituitary insufficiency.Lancet 1998;352:127-34K

8. Vance ML.Hypopituitarism.N England J.Med.1994;330:1651-62

9. Schrager S,Sabo L 2001.Sheehan syndrome:a rare complication of postpartum haemorrhage.J.Am. Board Fam.Pract.14(5):389-91

10. Ostuka F,Kageyama J,Ogura T,Hattori T,Makino H.Sheehan's syndrome of more than 30 years duration:an endocrine and MRI study of six cases. Endocr. J. $1998 ; 45: 451-8$
11. Gokalp D,Tuzcu A,Bahceci M,Arikan S,Bahceci S, and Pasa S 2009:Sheehan's syndrome as a rare cause of anaemia secondary to hypopituitarism. Annals of Haematology, 88,405-410

12. Prager D,Braunstein G.D. 1995:Pituitary disorders during pregnancy. Endocrinology Metabolism Clinics of North America, 24,1-14

13. Kaplun J.2008:Sequential Pituitary MR imaging in Sheehan's syndrome:Report of two cases. American Journal of Neuroradiology,29,941-943

14. Fleckman AM,Schubert UK,Danziger A,et al.Empty sella of normal size in Sheehan's syndrome.American Journal of Medicine 1983;75:585-91

15. LawayB.A.,Mir S.A.,Bashir M.I.,Bhat J.R.,Samoon J,Zargar A.H. 2011: Prevalence of haematological abnormalities in patients with Sheehan's syndrome: Response to replacement of glucocorticoids and thyroxine. Pituitary, March 2011,14(1)39-43. 